\title{
Microstepping Control of Ultrasonic Stepping Motors
}

\author{
K. T. Chau, Senior Member, IEEE, Bin Shi, Min-Qiang Hu, Long Jin, and Ying Fan, Student Member, IEEE
}

\begin{abstract}
The ultrasonic stepping motor (USSM) using spatially shifted standing vibrations shows the advantages of high torque, good controllability, and open-loop operation. Due to the segmentation problem of piezoelectric materials, the corresponding step size is practically limited. The purpose of this paper is to propose and implement microstepping control of this USSM. Different from the available half-step operation, the proposed control simultaneously varies both the combination of phase excitations and the magnitude of applied voltages in such a way that the desired step size can be attained. Digital implementation and experimental verification are given to validate the proposed microstepping control.
\end{abstract}

Index Terms-Motor control, piezoelectric, stepping motor, ultrasonic motor.

\section{INTRODUCTION}

$\mathbf{T}$ HE traveling-wave ultrasonic motor (TWUSM) has become attractive for servomechanism, since it offers the distinct advantages of high torque density, lightweight, compact size, fast response, no electromagnetic interference (EMI), quiet operation, and power-down holding torque capability [1]-[3]. Nevertheless, the TWUSM still suffers from the drawback of closed-loop operation, thus desiring precision sensing devices [4], [5]. In order to get rid of this bulky and costly closed-loop system, the first ultrasonic stepping motor (USSM) was proposed in 1993 [6]. However, this motor generally involves many projections on the stator and many slits in the rotor, hence, suffering from the difficulty in controlling the degenerated modes [7], [8].

Recently, a viable USSM using spatially shifted standing vibrations has been proposed in which the stator does not have any projections [9]. This motor shows the definite advantages of high torque, good controllability, and open-loop operation. However, due to the segmentation problem of piezoelectric materials, which are usually made of lead zirconate titanate (PZT), the corresponding step size or the number of steps per revolution is practically limited. Very recently, an attempt has been made to improve the step size of this USSM by borrowing

Paper IPCSD-05-095, presented at the 2004 Industry Applications Society Annual Meeting, Seattle, WA, October 3-7, and approved for publication in the IEEE TRANSACTIONS ON INDUSTRY APPLICATIONS by the Electric Machines Committee of the IEEE Industry Applications Society. Manuscript submitted for review February 1, 2005 and released for publication December 15, 2005. This work was supported by a Grant (Project HKU7159/03E) from the Research Grants Council of Hong Kong.

K. T. Chau, B. Shi, and Y. Fan are with the Department of Electrical and Electronic Engineering, The University of Hong Kong, Hong Kong (e-mail: ktchau@eee.hku.hk; binshi@eee.hku.hk; yfan@eee.hku.hk).

M.-Q. Hu and L. Jin are with the Department of Electrical Engineering, Southeast University, Nanjing 210096, China (e-mail: mqhu@ @eu.edu.cn; jinlong@seu.edu.cn).

Digital Object Identifier 10.1109/TIA.2005.863898

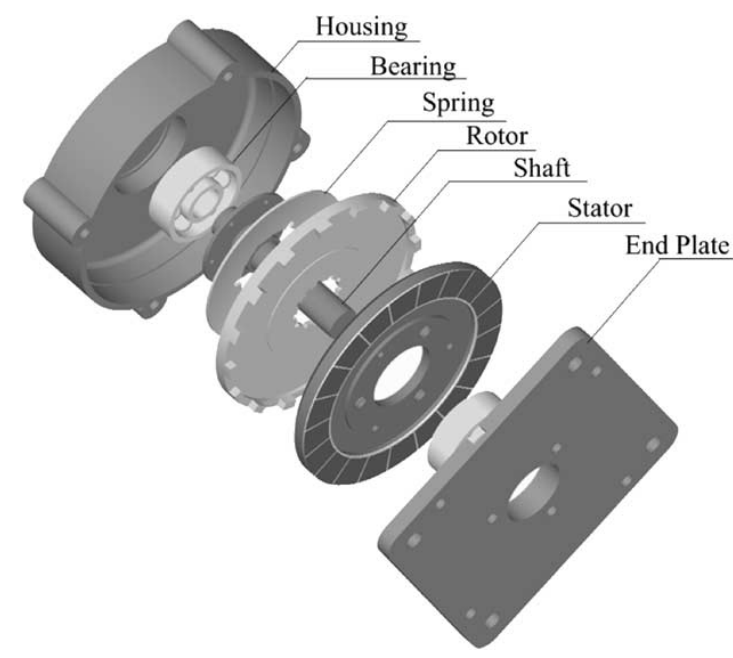

Fig. 1. USSM configuration.

the half-step operation of the conventional electromagnetic stepping motor [10].

Following the idea in [10], the purpose of this paper is to propose and implement the microstepping control of the USSM using the principle of spatially shifted standing vibrations. Different from the previous half-step operation, which successively conducts single-phase-on and two-phase-on excitation modes, the proposed microstepping control simultaneously varies both the combination of phase excitations and the magnitude of excitations in such a way that the desired step size can be attained. Different from the microstepping control of electromagnetic stepping motors in which the phase currents are modulated [11], the proposed microstepping control is to modulate the applied phase voltages.

In Section II, the operating principle of the USSM using spatially shifted standing vibrations will be briefly described. Then, the newly proposed microstepping control of this USSM will be discussed in Section III. Section IV will be devoted to present the implementation of the whole system. In Section V, experimental characteristics of the prototype will be given to verify the proposed microstepping operation. Finally, conclusions will be drawn in Section VI.

\section{PRINCIPLE OF Operation}

The configuration of the USSM using spatially shifted standing vibrations is depicted in Fig. 1. It is an 80-step $(N=80)$ USSM with the order of vibration mode $n=8$, the number of spatial phase shifts (which is equivalent to the number of driving phases) $p=5$, the number of electrode divisions $q=20$, and the number of sections $m=4$ to excite a mode 


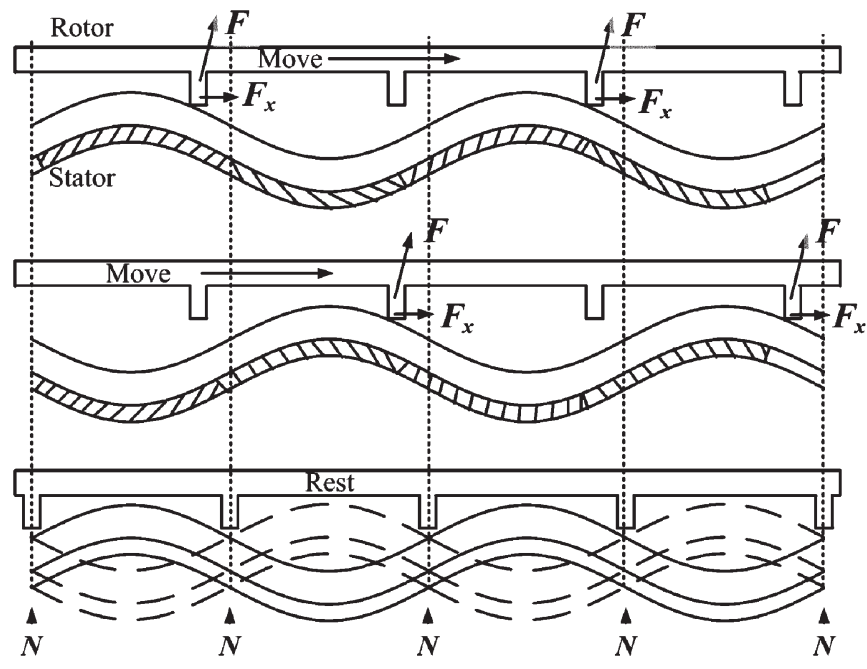

Fig. 2. Principle of stepping.

TABLE I

EXCITATION SEQUENCE OF FULL-STEP OPERATION

\begin{tabular}{|c|c|c|c|c|c|}
\hline & 1 & 2 & 3 & 4 & 5 \\
\hline A & $X$ & & & & \\
\hline$B$ & & $X$ & & & \\
\hline C & & & $X$ & & \\
\hline D & & & & $X$ & \\
\hline E & & & & & $X$ \\
\hline
\end{tabular}

each time. The rotor consists of 16 blades machined at the contact surface with the stator.

As shown in Fig. 1, the source of vibrations is the piezoelectric electrodes firmly attached beneath the stator. When these piezoelectric electrodes are excited, the stator vibrates accordingly. The spring functions to provide a constant pressure to keep the rotor onto the stator, hence enabling force transmission from the stator to the rotor. The shaft is attached with the rotor, and mounted onto the housing and end plate by two bearings.

Fig. 2 shows the principle of stepping of the USSM. When the electrodes of phase A are fed by the applied voltage, the standing-wave vibration is excited. Then, the force $F$ is applied to the rotor by the flexural bending vibration of the stator. The corresponding horizontal component $F_{x}$ pushes the rotor moving to the nodal line position of the stator. By exciting the phases in sequence, the nodal line moves along the circumference of the stator. Thus, the rotor moves with the nodal line. The sequence of excitation is shown in Table I.

The design criteria and design procedure of this USSM have been discussed in [12]. In this paper, the normal operation (namely, the small step size operation) of the USSM is considered, whereas the abnormal operation (namely, the large step size operation) is ignored. In short, the design parameters are governed by [12]

$$
\begin{aligned}
q & =\frac{2 n N}{N-2 n} \\
p & =\frac{N}{2 n} \\
m & =\frac{q}{p} .
\end{aligned}
$$

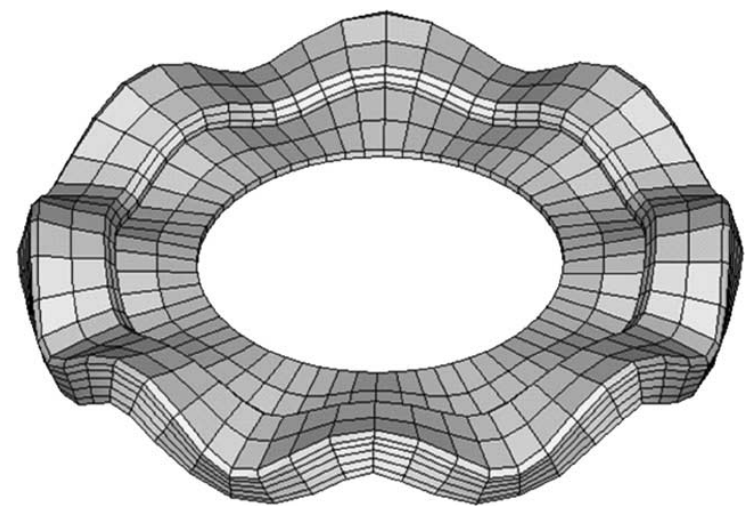

Fig. 3. FEM simulated vibration pattern.

In order to determine the driving frequency to excite the desired vibration mode, a vibration analysis is conducted. In general, a commercially available finite element method (FEM) software package can be utilized. The analysis result is shown in Fig. 3, in which the $B_{08}$ vibration mode is adopted. Hence, the resonant frequency can be calculated as $44.9 \mathrm{kHz}$. Based on this initial estimation, the actual driving frequency is determined by trial and error, and found to be $40.5 \mathrm{kHz}$.

\section{Microstepping Control}

In order to illustrate the proposed microstepping-control approach, three typical fractional-step operations (namely, the half-step, one-third-step, and two-third-step operations) are graphically depicted. Notice that the number of microsteps can be flexibly controlled to achieve different fractional steps. Theoretically, the size of these microsteps is unconstrained; however, its size is practically limited by the physical tolerances and manufacturing imperfections of the USSM during prototyping.

Fig. 4(a) shows the concept of half-step operation. The corresponding movement equals half of one step, hence, the term half-step operation. The corresponding excitation sequence is shown in Table II. Extending this concept, the adjustment of both the combination of phase excitations and the magnitude of applied voltages can further subdivide the original step size.

The steps from phase A to B are adopted for exemplification. When phases A and B are excited, the spatial displacement distribution of the vibration can be expressed as

$$
\begin{aligned}
& f_{\mathrm{a}}=A \sin n \theta \\
& f_{\mathrm{b}}=B \sin n\left(\theta-\theta_{\mathrm{s}}\right)
\end{aligned}
$$

where $\theta_{\mathrm{s}}=2 \pi / N$ denotes the spatial distance between phases $\mathrm{A}$ and $\mathrm{B}$, and $A$ and $B$ denote the corresponding vibration amplitudes. When phases A and B are excited simultaneously, the spatial displacement distribution can be expressed as

$$
f_{\mathrm{ab}}=f_{\mathrm{a}}+f_{\mathrm{b}} .
$$

Substituting (4) and (5) into (6) yields

$$
f_{\mathrm{ab}}=F_{\mathrm{ab}} \sin n(\theta-\varphi)
$$




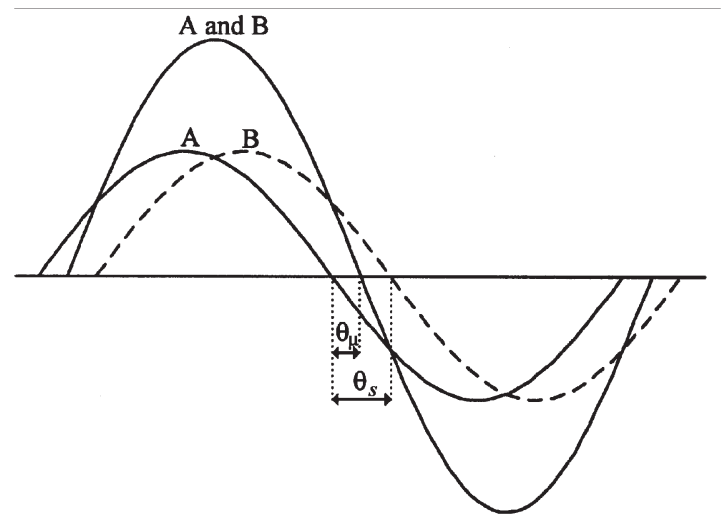

(a)

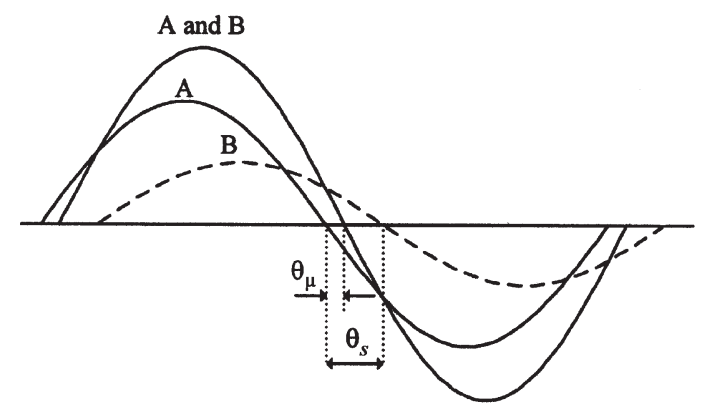

(b)

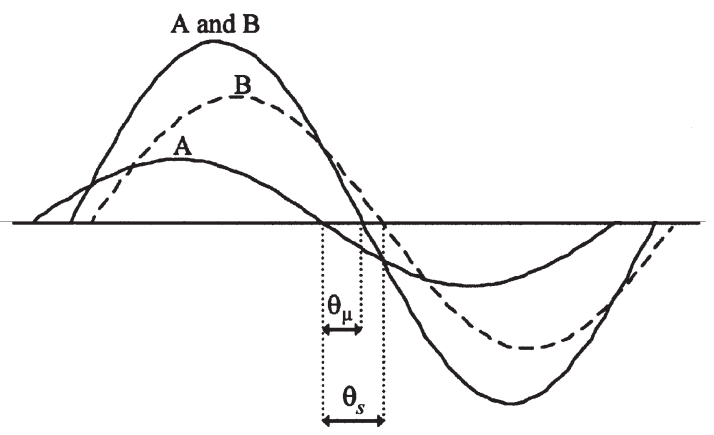

(c)

Fig. 4. Principle of microstep operations. (a) $50 \%$ step. (b) $33 \%$ step. (c) $67 \%$ step.

where the corresponding amplitude and phase difference are given by

$$
\begin{aligned}
F_{\mathrm{ab}} & =\sqrt{\left(A+B \cos n \theta_{\mathrm{s}}\right)^{2}+\left(B \sin n \theta_{\mathrm{s}}\right)^{2}} \\
\varphi & =\frac{1}{n} \arctan \left(\frac{\left(\frac{B}{A}\right) \sin n \theta_{\mathrm{s}}}{1+\left(\frac{B}{A}\right) \cos n \theta_{\mathrm{s}}}\right) .
\end{aligned}
$$

Thus, when the excitation switches from phase A to the simultaneous excitation of both phases A and B, the microstep angle $\theta_{\mu}$ is equal to the angle shift from the initial nodal line (the zerocrossing point of $f_{\mathrm{a}}$ ) to the new nodal line (the zero-crossing point of $\left.f_{\mathrm{ab}}\right)$. Hence, it yields

$$
\theta_{\mu}=\varphi
$$

TABLE II

EXCITATION SEQUENCE OF 50\%-STEP OPERATION

\begin{tabular}{|l|l|l|l|l|l|l|l|l|l|l|}
\hline & 1 & 2 & 3 & 4 & 5 & 6 & 7 & 8 & 9 & 1 \\
& & & & & & & & & & 0 \\
\hline A & $\mathrm{X}$ & $\mathrm{X}$ & & & & & & & & $\mathrm{X}$ \\
\hline $\mathrm{B}$ & & $\mathrm{X}$ & $\mathrm{X}$ & $\mathrm{X}$ & & & & & & \\
\hline C & & & & $\mathrm{X}$ & $\mathrm{X}$ & $\mathrm{X}$ & & & & \\
\hline D & & & & & & $\mathrm{X}$ & $\mathrm{X}$ & $\mathrm{X}$ & & \\
\hline E & & & & & & & & $\mathrm{X}$ & $\mathrm{X}$ & $\mathrm{X}$ \\
\hline
\end{tabular}

TABLE III

EXCITATION SEQUENCE OF 33\%-STEP OPERATION

\begin{tabular}{|l|l|l|l|l|l|l|l|l|l|l|l|l|l|l|l|}
\hline & 1 & 2 & 3 & 4 & 5 & 6 & 7 & 8 & 9 & 1 & 1 & 1 & 1 & 1 & 1 \\
& & & & & & & & & & 0 & 1 & 2 & 3 & 4 & 5 \\
\hline A & $\mathrm{X}$ & $\mathrm{X}$ & $\mathrm{X}$ & & & & & & & & & & & $\mathrm{X}$ & $\mathrm{X}$ \\
\hline $\mathrm{B}$ & & $\mathrm{X}$ & $\mathrm{X}$ & $\mathrm{X}$ & $\mathrm{X}$ & $\mathrm{X}$ & & & & & & & & & \\
\hline C & & & & & $\mathrm{X}$ & $\mathrm{X}$ & $\mathrm{X}$ & $\mathrm{X}$ & $\mathrm{X}$ & & & & & & \\
\hline $\mathrm{D}$ & & & & & & & & $\mathrm{X}$ & $\mathrm{X}$ & $\mathrm{X}$ & $\mathrm{X}$ & $\mathrm{X}$ & & & \\
\hline $\mathrm{E}$ & & & & & & & & & & & $\mathrm{X}$ & $\mathrm{X}$ & $\mathrm{X}$ & $\mathrm{X}$ & $\mathrm{X}$ \\
\hline
\end{tabular}

TABLE IV

EXCITATION SEQUENCE OF 67\%-STEP OPERATION

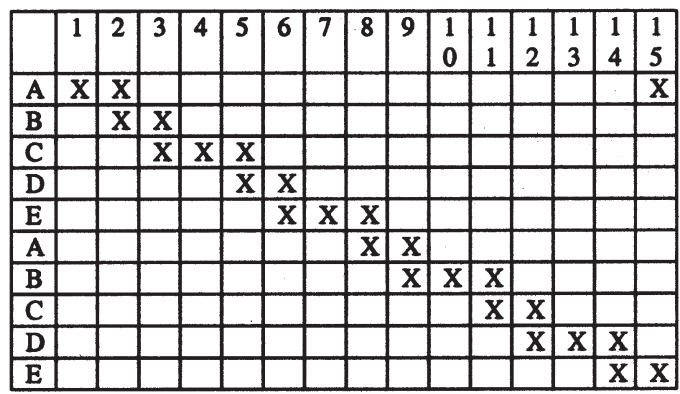

Substituting (9) into (10), $\theta_{\mu}$ can be expressed as

$$
\theta_{\mu}=\frac{1}{n} \arctan \left(\frac{\left(\frac{B}{A}\right) \sin n \theta_{\mathrm{s}}}{1+\left(\frac{B}{A}\right) \cos n \theta_{\mathrm{s}}}\right) .
$$

After rearrangement, the voltage-amplitude ratio $(B / A)$ can be expressed in terms of $\theta_{\mu}$ as given by

$$
\left(\frac{B}{A}\right)=\frac{\tan n \theta_{\mu}}{\sin n \theta_{\mathrm{s}}-\tan n \theta_{\mu} \cos n \theta_{\mathrm{s}}} .
$$

It indicates that once the microstep size is given, there is an appropriate voltage-amplitude ratio. Fig. 4 illustrates the realization of the 50\% step (half-step), 33\% step (one-third step), and 67\% step (two-third step) of the USSM when the values of $(B / A)$ are chosen as $1,0.5$, and 2, respectively. The corresponding excitation sequences are tabulated in Tables II-IV, respectively.

From Tables II and III, the numbers of microsteps within a full step are 2 and 3, respectively. Since they are both integers, the excitation sequences are repeated after each cycle. On the other hand, from Table IV, the number of microsteps within a full step is $3 / 2$, so that the excitation sequence can only be repeated after two cycles. Of course, an integer multiple of microsteps within a full step is preferred.

By using (11), when $n=8$ and $\theta_{\mathrm{s}}=4.5^{\circ}$, the relationship between $\theta_{\mu}$ and $(B / A)$ is plotted in Fig. 5, which can provide 


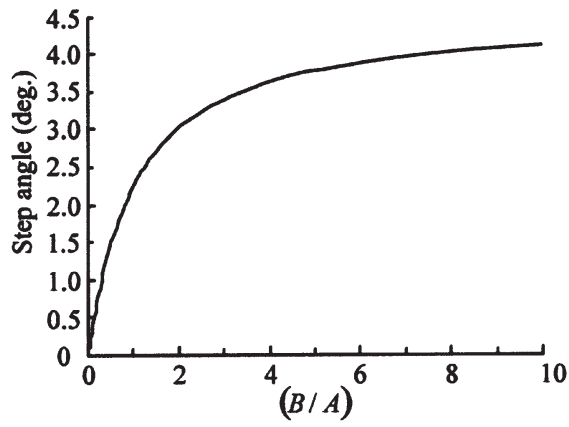

(a)

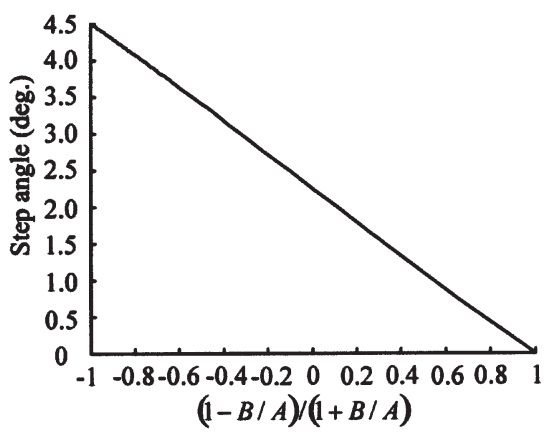

(b)

Fig. 5. Microstep angle versus voltage-amplitude ratio. (a) Nonlinear relation with $(B / A)$. (b) Almost linear relation with $(1-B / A) /(1+B / A)$.

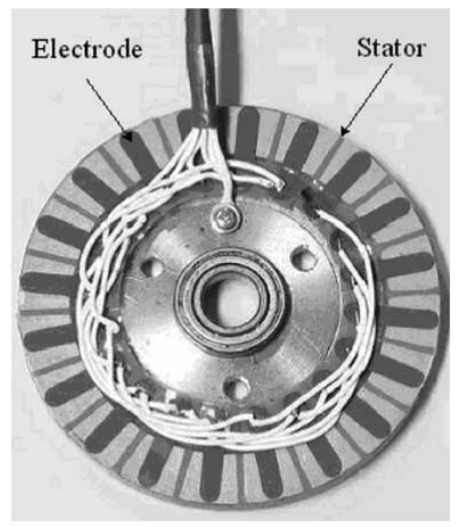

(a)

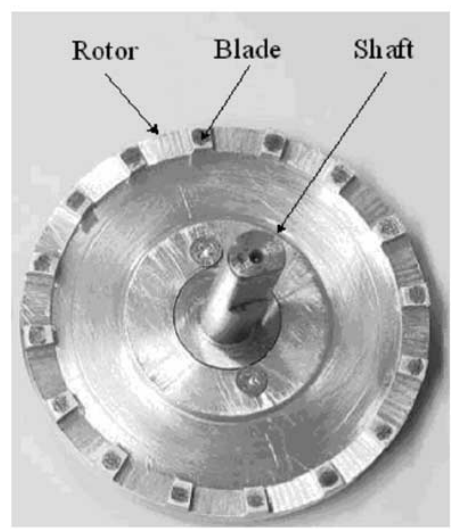

(b)

Fig. 6. USSM prototype. (a) Stator with 20 electrodes. (b) Rotor with 16 blades.
TABLE $\mathrm{V}$

PhysicAl PARAMETERS OF PROTOTYPE

\begin{tabular}{ll}
\hline Initial number of steps & 80 \\
Initial step size & $4.5^{\circ}$ \\
Order of vibration mode & 8 \\
Number of driving phases & 5 \\
Number of electrodes & 20 \\
Number of blades & 16 \\
\hline
\end{tabular}

TABLE VI

GeOMETRIC PARAMETERS OF PROTOTYPE

\begin{tabular}{ll}
\hline Inner radius of stator & $22.5 \mathrm{~mm}$ \\
Outer radius of stator & $30.0 \mathrm{~mm}$ \\
Height of stator & $3.0 \mathrm{~mm}$ \\
Height of electrodes & $0.5 \mathrm{~mm}$ \\
Inner radius of rotor & $26.0 \mathrm{~mm}$ \\
Outer radius of rotor & $29.0 \mathrm{~mm}$ \\
Height of rotor & $3.0 \mathrm{~mm}$ \\
Circumferential width of blades & $2.8 \mathrm{~mm}$ \\
Radial width of blades & $3.0 \mathrm{~mm}$ \\
Height of blades & $1.8 \mathrm{~mm}$ \\
Radius of shaft & $4.0 \mathrm{~mm}$ \\
Height of shaft & $36.0 \mathrm{~mm}$ \\
\hline
\end{tabular}

TABLE VII

SPECIFICATIONS OF PROTOTYPE

\begin{tabular}{ll}
\hline Driving frequency & $40.5 \mathrm{kHz}$ \\
Applied voltage & $70.7 \mathrm{~V}$ \\
Rated torque & $2.8 \mathrm{Ncm}$ \\
Maximum torque & $5.6 \mathrm{Ncm}$ \\
Maximum response time & $80 \mathrm{~ms}$ \\
\hline
\end{tabular}

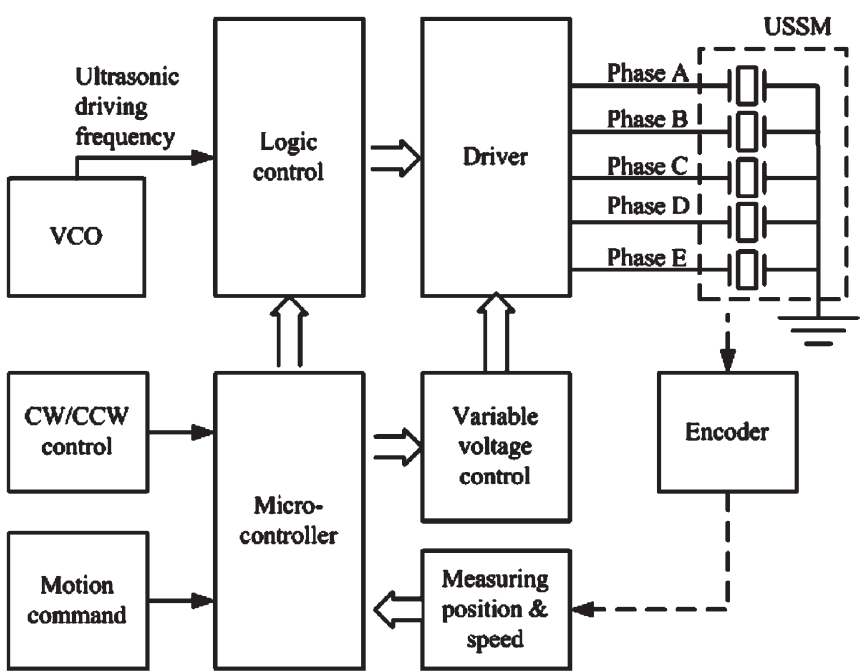

Fig. 7. Control and driving-circuit block diagram.

the designer an easy tool to select number of microsteps and the desired applied voltage amplitudes. It can be seen that the lower the $(B / A)$ is selected, the smaller the $\theta_{\mu}$, and hence, resulting in the larger number of microsteps.

\section{IMPLEMENTATION}

The USSM configuration shown in Fig. 1 , namely, $n=8$, $q=20, p=5$, and $m=4$, is prototyped. The corresponding 


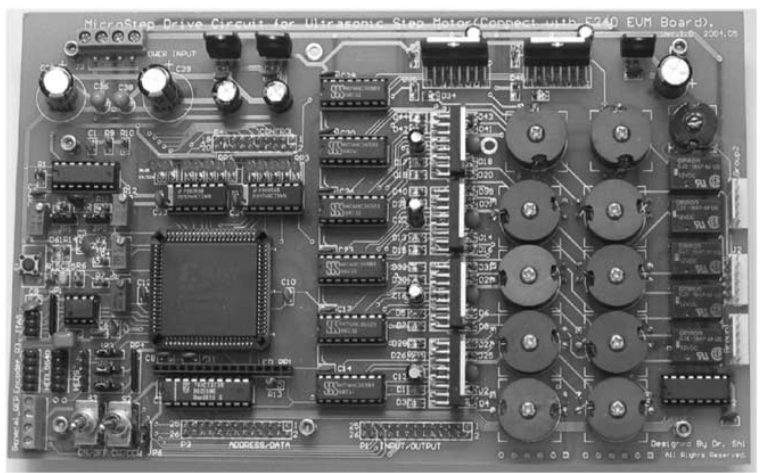

Fig. 8. Control and driving-circuit prototype.

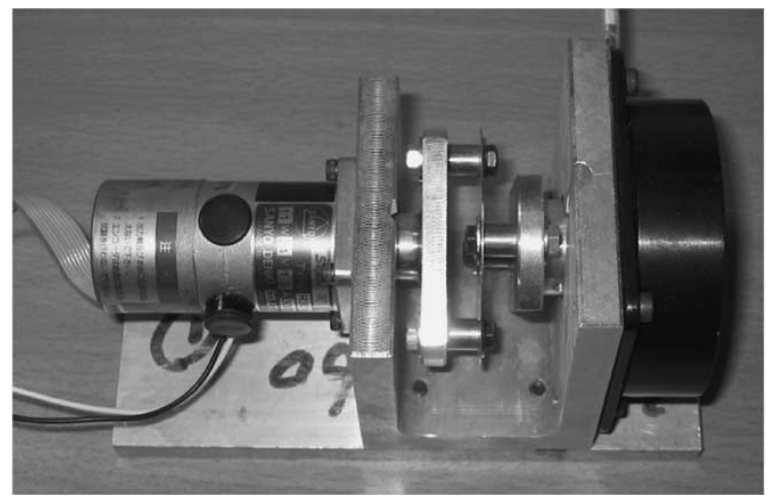

Fig. 9. Test bed of prototype.

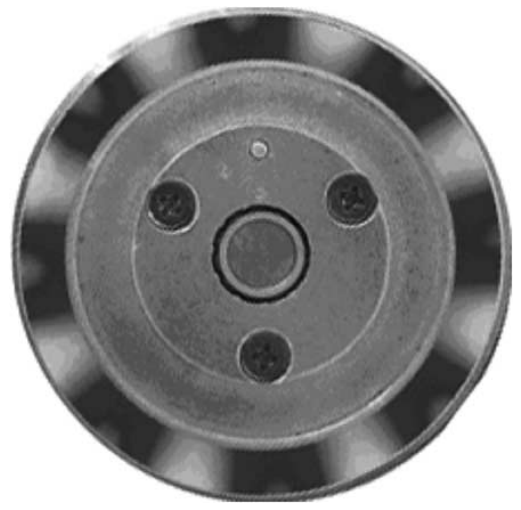

Fig. 10. Measured vibration pattern using laser Doppler vibrometer.

structure is shown in Fig. 6. Since the elastic modulus of phosphor bronze is insensitive to the varying temperature, it is selected as the material of the elastic ring of the stator. The rotor is made of aluminum because of its lightweight and easy machining properties. The physical and geometric parameters of this prototype are tabulated in Tables V and VI, respectively. Its typical specifications are also tabulated in Table VII.

To implement the microstepping movement, the control and driving-circuit block diagram shown in Fig. 7 is used. The hardware core is the low-cost TMS320F240 microcontroller, which offers the calculation of $(B / A)$ for a given $\theta_{\mu}$ or the number of microsteps, the output interfaces for generating control signals, as well as the input interfaces for receiving command and measured data. The motion command can be any pattern of stepping motions with the direction governed by the clockwise/

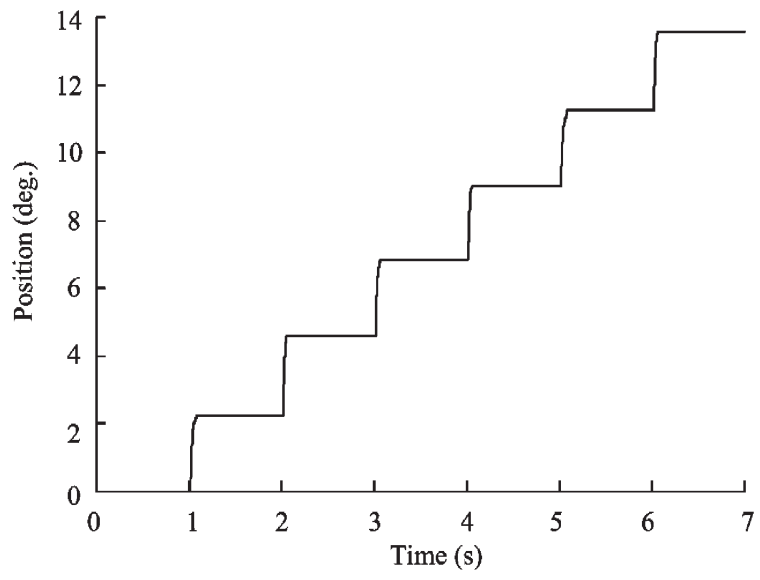

Fig. 11. Measured position response under 50\%-step operation for a command of six forward steps.

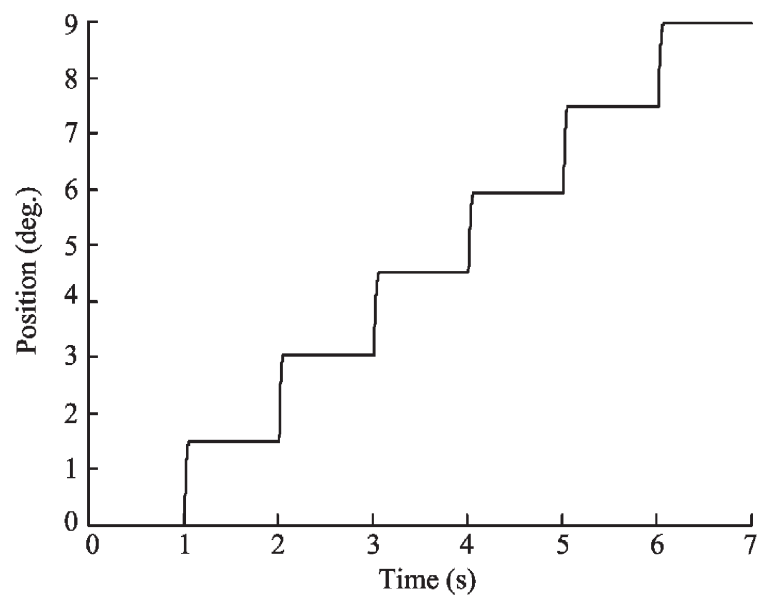

Fig. 12. Measured position response under 33\%-step operation for a command of six forward steps.

counterclockwise (CW/CCW) control unit. The ultrasonic driving frequency is generated by a voltage-controlled oscillator (VCO) unit. The variable voltage control unit is to generate the applied voltages based on the calculated $(B / A)$. After feeding the switching control signals and driving frequency into the logic control unit, the desired logic control signals result. Then, these logic control signals and the variable voltage control signal are amplified to drive the USSM. It should be noted that the whole system is under open-loop operation. The encoderand, hence, the measured position - and speed data are used for display only. Fig. 8 shows the prototype of this control and driving circuit.

Fig. 9 shows the test bed of the prototype for evaluation. A de servomotor is coupled to the USSM and works as the dynamometer. The load torque of this test bed can be flexibly controlled by electrically connecting a programmable electronic load to this de servomotor.

\section{EXPerimental CHARACTERISTICS}

Firstly, the vibration mode, namely $B_{08}$, is experimentally verified by using a laser Doppler vibrometer. Fig. 10 shows the measured spatial distribution of the vibration when phase $\mathrm{A}$ is 


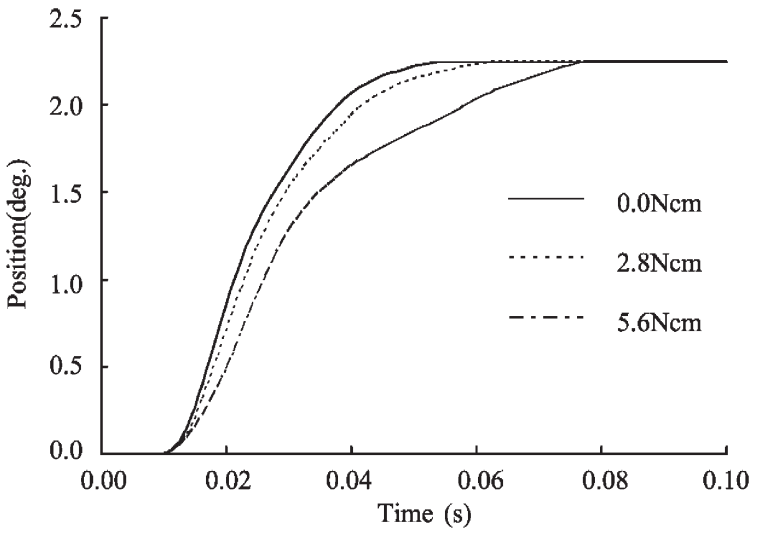

Fig. 13. Measured transient position response under 50\%-step operation at different loads.

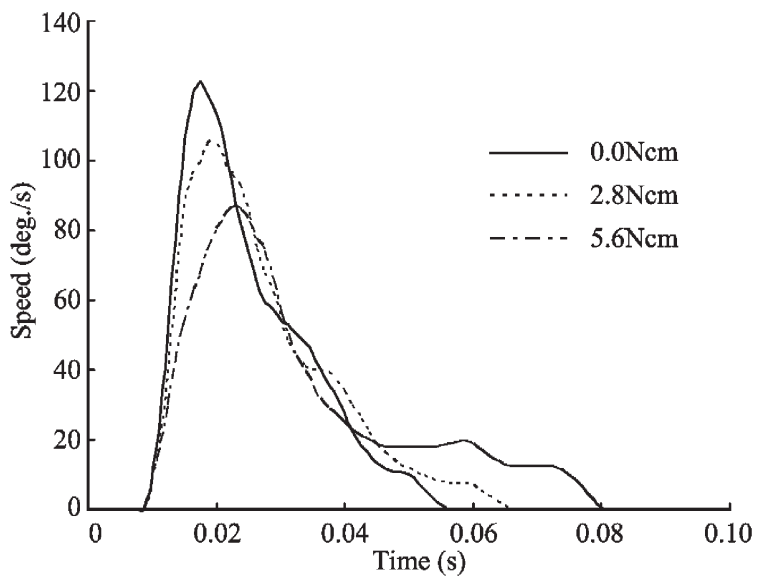

Fig. 14. Measured transient speed response under 50\%-step operation at different loads.

excited, which agrees with the FEM simulated vibration pattern shown in Fig. 3.

Secondly, the dynamic characteristics of the proposed microstepping-control approach for the USSM are investigated. Two integer multiples of microsteps, namely the 50\%-step and $33 \%$-step operations, are implemented. Fig. 11 shows the position response for a command of six forward steps when microstepping control is activated for a 50\%-step operation. Similarly, the position response under 33\%-step operation is shown in Fig. 12. It is obvious that the measured responses well verify the accuracy of microstep angles $\left(2.25^{\circ}\right.$ for $50 \%$ step operation and $1.5^{\circ}$ for $33 \%$-step operation).

Finally, the transient performances of the proposed approach for the USSM are investigated. A step command is adopted for illustration. Figs. 13 and 14 show the measured transient position and speed responses at different load torques, respectively. It can be found that the response times are all less than $80 \mathrm{~ms}$, confirming that the USSM can offer excellent transient performances.

\section{CONCLUSION}

In this paper, a new microstepping-control approach has been proposed and implemented for the USSM using spatially shifted standing vibrations. The key is to simultaneously adjust both the combination of phase excitations and the correspond- ing voltage-amplitude ratio in such a way that the desired step size can be attained. Digital implementation and experimental characteristics of the USSM at the 50\%-step and 33\%-step operations are given to verify the proposed microstepping control.

\section{REFERENCES}

[1] T. Sashida and T. Kenjo, An Introduction to Ultrasonic Motors. New York: Oxford Science, 1993

[2] S. Ueha and Y. Tomikawa, Ultrasonic Motors: Theory and Applications. New York: Oxford Science, 1993.

[3] K. Uchino, "Piezoelectric ultrasonic motors: Overview," Smart Mater. Struct., vol. 7, no. 3, pp. 273-285, Jun. 1998.

[4] K. T. Chau and S. W. Chung, "Servo position control of ultrasonic motors using fuzzy neural network," Electr. Mach. Power Syst., vol. 29, no. 3, pp. 229-246, 2001

[5] $\frac{\text {, }}{2}$ "Servo speed control of traveling-wave ultrasonic motors using pulse width modulation," Electr. Power Compon. Syst., vol. 29, no. 8, pp. 707-722, Aug. 2001.

[6] X. Chen, C. Kusakabe, Y. Tomikawa, and T. Takano, "Rotor displacement of the ultrasonic motor having an angular displacement self-correction function," Jpn. J. Appl. Phys., vol. 32, no. 9B, pt. 1, pp. 4198-4201, Sep. 1993.

[7] C. Kusakabe, "Effect of pressing force applied to a rotor on disk-type ultrasonic motor driven by self-oscillation," Jpn. J. Appl. Phys., vol. 37, no. 5B, pt. 1, pp. 2966-2969, May 1998.

[8] S. He, W. Chen, X. Tao, and Z. Chen, "Standing wave bi-directional linearly moving ultrasonic motor," IEEE Trans. Ultrason., Ferroelectr. Freq. Control, vol. 45, no. 5, pp. 1133-1139, Sep. 1998.

[9] K. Nakamura, J. Margairaz, T. Ishii, and S. Ueha, "Ultrasonic stepping motor using spatially shifted standing vibrations," IEEE Trans. Ultrason., Ferroelectr., Freq. Control, vol. 44, no. 4, pp. 823-827, Jul. 1997.

[10] K. T. Chau, B. Shi, and M. Q. Hu, "A design method and half-step operation for ultrasonic stepping motors," IEEE Trans. Ind. Appl., vol. 39 , no. 4, pp. 953-960, Jul./Aug. 2003.

[11] D. Xu and Y. Jiang, "A method and implementation of fully digitized continuous microstep for step motor," in Proc. IEEE Int. Electric Machines and Drives Conf., Milwaukee, WI, 1997, pp. TC2/9.1-TC2/9.3.

[12] K. T. Chau, B. Shi, M. Q. Hu, and S. W. Chung, "Design and control of a new ultrasonic stepping motor," in Conf. Rec. IEEE-IAS Annu. Meeting, Pittsburgh, PA, 2002, pp. 2259-2266.

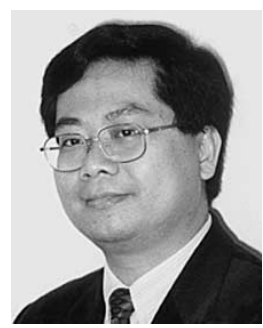

K. T. Chau (M'89-SM'04) received the B.Sc. (Eng.) (first-class honors), M. Phil., and Ph.D. degrees in electrical and electronic engineering in 1988, 1991, and 1993, respectively, from The University of Hong Kong, Hong Kong.

Currently, he serves as Associate Professor and Director of the International Research Center for Electric Vehicles at The University of Hong Kong. His teaching and research interests focus on three main areas: electric drives, electric vehicles, and power electronics. In these areas, he has published about 200 refereed technical papers and many industrial reports. He has also served as the Chairperson and as a member of the organizing committees for many international conferences.

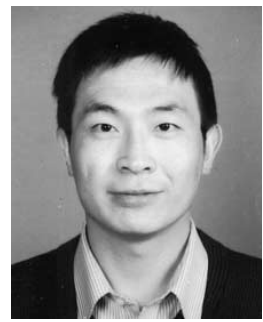

Bin Shi was born in Shanxi, China, in 1973. He received the B.Sc. (Eng.) and Ph.D. degrees in electrical engineering in 1995 and 2001, respectively, from Southeast University, Nanjing, China.

$\mathrm{He}$ is currently a Research Associate in the Department of Electrical and Electronic Engineering, The University of Hong Kong, Hong Kong. His current research interests include motor control, ultrasonic-motor modeling, and power electronics. 


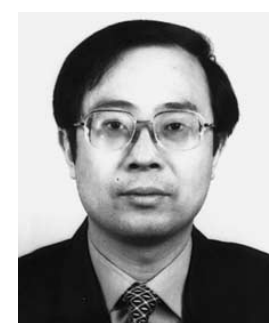

Min-Qiang Hu was born in Jiangsu, China, in 1961. He received the B.Sc. (Eng.) and M. Phil. degrees in electrical power systems and automation in 1982 and 1985, respectively, from Tianjin University, Tianjin, China, and the Ph.D. degree in electrical engineering in 1989 from Huazhong University of Technology, Wuhan, China.

In 1989, he joined the Department of Electrical Engineering, Southeast University, Nanjing, China, and has served as the Head of the Department. Currently, he serves as Professor, Vice Dean of the Faculty of the Graduate School, and Assistant Chancellor. His main research areas include electromagnetic-field theory, electric motors, and electric-energy utilization. He is the holder of several patents, has authored over 90 publications, and delivered many presentations. He is currently a member of the Technology Division of the Science and Technology Committee in the Ministry of Education, and Director of the Jiangsu Electrical Technology Institute.

Dr. Hu is a Council Member of the Chinese Electrical Engineering Association.

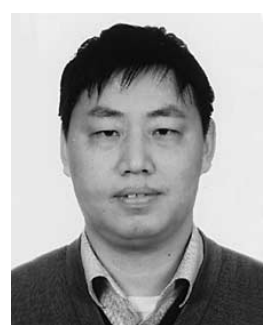

Long Jin received the M.Sc. (Eng.) degree in electrical engineering from the Department of Automation Control, Nanjing University of Aeronautics and Astronautics, Nanjing, China, in 1993, and the Ph.D. degree in vibration engineering from the Institute of Vibration Engineering Research, Nanjing University of Aeronautics and Astronautics, in 1997.

From 1997 to 1999, he was a Postdoctoral Fellow at the Institute of System Engineering Research and the Department of Electrical and Electronic Engineering, Southeast University, Nanjing, China. Since 2000, he has been an Associate Professor in the Department of Electrical Engineering, Southeast University. He has published over 40 technical papers and his research activities include ultrasonic motors and their control systems and high intensity discharge (HID) lamp ballast circuits.

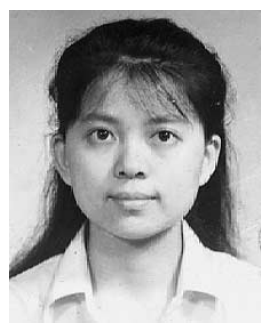

Ying Fan (S'04) received the B.Sc. (Eng.) and M.Sc. (Eng.) degrees in electrical engineering from the Department of Electrical Engineering, Nanjing University of Astronautics and Aeronautics, Nanjing, China, in 1991 and 1996, respectively. She is currently working toward the Ph.D. degree in electrical and electronic engineering at The University of Hong Kong, Hong Kong.

Her research interests focus on electric machine design, motor drive control, power electronics, modeling, and simulation. 